\title{
APLIKASI KESEHATAN MENGGUNAKAN METODE EPIDEMIOLOGI SKRINING TES UNTUK KARYAWAN CV.ANNISA
}

\author{
Jauhari Maulani \\ Fakultas Teknologi Informasi, Universitas Islam Kalimantan Muhammad Arsyad Al Banjari Banjarmasin \\ Email : jauharimaulani@gmail.com
}

\begin{abstract}
Abstrak
Keterangan berbadan sehat juga menjadi salah satu prasyarat sebagai karyawan pada perusahaan CV. Annisa, yang mana seorang karyawan harus dinyatakan berbadan sehat untuk membuktikan bahwa seorang karyawan tersebut sehat dan siap berkerja, tanpa ada halangan ke tidak sehatan yang berat. Pemeriksan kesehatan yang tidak bisa dilakukan langsung di tempat perusahaan CV. Annisa dan membutuhkan waktu lebih untuk pemeriksaan serta mendapatkan hasil kesehatannya. Pada pengujian dan pemeriksaan kesehatan dengan menggunakan metode epidemiologi skrining atau penapisan yang berupa pertanyaan seputar tentang penyebab penyakit atau riwayat kesehatan seseorang atau keluarganya, dari pertanyaan dan penarikan kesimpulan yang sifatnya masih manual, baik yang tertulis atau tanya jawab, maka dilakukan pembuatan aplikasi menggunakan sistem pakar, ke ahlian pakar kesehatan dalam penerapan metode epidemiologi skrining tes di adopsi ke dalam sistem komputerisasi agar komputer dapat melakukan pemeriksaan kesehatan seperti yang biasa dilakukan oleh para ahli (Dokter). Pembangunan aplikasi kesehatan menggunakan metode epidemiologi skrining tes untuk karyawan CV. Annisa dapat melakukan pemeriksaan kesehatan membuat skrining tes kesehatan secara cepat dan efisien sesuai dengan data yang ada, dengan menghasilkan langsung data kesehatan karyawannya.
\end{abstract}

Kata Kunci: Aplikasi, Epidemiologi, Skrining, Kesehatan

\section{PENDAhUluAN}

Manusia yang kadang terlihat sehat dari fisik, masih belum tentu sehat secara total. Ada kondisi dimana kesehatan manusia yang mungkin kurang sehat atau terindikasi penyakit tertentu, namun tidak diketahui penyakitnya. Mengetahui penyakit seorang manusia harus memeriksakan dirinya kepada para ahli kesehatan, baik dokter ahli penyakit secara umum yang ada di rumah sakit, klinik atau puskesmas. Hasil pemeriksaan kesehatan tersebut memberikan informasi kesehatan seseorang, yang pada umumnya di informasikan dalam bentuk surat keterangan sehat.

Keterangan berbadan sehat juga menjadi salah satu prasyarat sebagai karyawan pada perusahaan CV. Annisa, yang mana seorang karyawan harus dinyatakan berbadan sehat untuk membuktikan bahwa seorang karyawan tersebut sehat dan siap berkerja, tanpa ada halangan ke tidak sehatan yang berat. Pemeriksan kesehatan yang tidak bisa dilakukan langsung di tempat perusahaan CV. Annisa dan membutuhkan waktu lebih untuk pemeriksaan serta mendapatkan hasil kesehatannya. Maka melalui penelitian ini, peneliti membuat suatu aplikasi yang berhubungan dengan pemeriksaan kesehatan.

Disiplin ilmu kesehatan masyarakat dengan metode epidemiologi disampaikan oleh last (2001) sebagai distribusi, determinan keadaan atau peristiwa terkait kesehatan pada perkembangannya serta penerapannya untuk mengenanggulangi masalah kesehatan, sedangkan Komisi penyakit kronis AS (1951) pada kamus epidemiologi (A Dictionary of 
Epidemiology), identifikasi penyakit, kecacatan yang belum dikenali oleh manusia dengan menerapkan pemeriksaan atau pengujian yang dapat diterapkan dengan cepat, merupakan skrining atau penapisan. Skrining atau penapisan sebagai tes kesehatan yang memilah atau memisahkan orang - orang yang terlihat sehat untuk di kelompokan menjadi kelompok yang mungkin memiliki penyakit dan kelompok orang yang mungkin sehat.

Pada pengujian dan pemeriksaan kesehatan dengan menggunakan skrining atau penapisan yang berupa pertanyaan seputar tentang penyebab penyakit atau riwayat kesehatan seseorang atau keluarganya. Dari pertanyaan dan penarikan kesimpulan yang sifatnya masih manual baik yang tertulis atau tanya jawab, maka pada pembuatan aplikasi menggunakan sistem pakar, ke ahlian pakar kesehatan dalam penerapan skrining tes di adopsi ke dalam sistem komputerisasi agar komputer dapat menyelesaikan masalah seperti yang biasa dilakukan oleh para ahli.

Tujuan dari penelitian ini dilaksanakan agar mempermudah mendeteksi kesehatan karyawan CV.Annisa yang digunakan untuk salah satu prasyarat kontrak pekerjaan dengan aplikasi kesehatan menggunakan metode epidemiologi skrining tes.

Berdasarkan latar belakang diatas, maka rumusan masalahnya menganalisis dan merancang Aplikasi Kesehatan Menggunakan Metode Skrining Tes, guna lebih mudah dalam mendeteksi kesehatan karyawan Cv. Annisa.

\section{METODE PENELITIAN}

\section{Sistem Pakar}

Sistem pakar (expert system) merupakan sistem yang berusaha mengadopsi pengetahuan manusia ke komputer, agar komputer dapat menyelesaikan masalah seperti yang biasa dilakukan oleh para ahli. Sistem pakar yang baik dirancang agar dapat menyelelasikan suatu permasalahan tertentu dengan meniru kerja dari para ahli. Dengan sistem pakar ini, orang awampun dapat menyelesaikan masalah yang cukup rumit yang sebenarnya hanya dapat diselesaikan dengan bantuan para ahli. Bagi para ahli, sistem pakar ini juga akan membantu aktivitasnya sebagai asisten yang sangat berpengalaman.

Ada beberapa definisi tentang sistem pakar, antara lain :

1. Menurut Durkin : Sistem pakar adalah suatu program komputer yang dirancang untuk memodelkan kemampuan penyelesaian masalah yang dilakukan seorang pakar.

2. Menurut Ignizio : Sistem pakar adalah suatu model dan prosedur yang berkaitan, dalam suatu domain tertentu, yang mana tingkat keahliannya dapat dibandingkan dengan keahlian seorang pakar.

Menurut Giarratano dan Riley : Sistem pakar adalah suatu sistem komputer yang bisa menyamai atau meniru kemampuan seorang pakar.

Menurut Efraim Turban, konsep dasar sistem pakar mengandung : keahlian, ahli, pengalihan keahlian, inferensi, aturan dan kemampuan menjelaskan. Keahlian adalah suatu kelebihan penguasaan pengetahuan di bidang tertentu yang diperoleh dari pelatihan, membaca atau pengalaman. Seorang ahli adalah seseorang yang mampu menjelaskan suatu tanggapan, mempelajari hal-hal baru seputar topik permasalahan (domain), menyusun kembali pengetahuan jika dipandang perlu, memecah aturan-aturan jika dibutuhkan, dan menentukan relevan tidaknya keahlian mereka. Pengalihan keahlian dari para ahli ke komputer untuk kemudian dialihkan lagi ke orang lain yang bukan ahli, merupakan tujuan utama dari sistem pakar Proses ini membutuhkan 4 aktivitas yaitu :
a. Tambahan pengetahuan (dari para ahli atau sumber-sumber lainnya).
b. Representasi pengetahuan (ke komputer).
c. Inferensi pengetahuan.
d. Pengalihan pengetahuan ke user.

Pengetahuan yang disimpan di komputer disebut dengan nama basis pengetahuan. Ada 2 tipe pengetahuan, yaitu : fakta dan prosedur (biasanya berupa aturan). Salah satu fitur yang harus dimiliki oleh sistem pakar adalah kemampuan untuk menalar. Jika keahliankeahlian sudah tersimpan sebagai basis pengetahuan dan sudah tersedia program yang 
mampu mengakses basisdata, maka komputer harus dapat diprogram untuk membuat inferensi. Proses inferensi ini dikemas dalam bentuk motor inferensi (inference engine).

\section{Keuntungan Sistem Pakar}

Secara garis besar, banyak manfaat yang dapat diambil dengan adanya sistem pakar, antara lain :

1. Memungkinkan orang awam bisa mengerjakan pekerjaan para ahli.

2. Bisa melakukan proses secara berulang secara otomatis.

3. Menyimpan pengetahuan dan keahlian para pakar.

4. Meningkatkan output dan produktivitas.

5. Meningkatkan kualitas.

6. Mampu mengambil dan melestarikan keahlian para pakar (terutama yang termasuk keahlian langka).

7. Mampu beroperasi dalam lingkungan yang berbahaya.

8. Memiliki kemampuan untuk mengakses pengetahuan.

9. Memiliki reliabilitas.

10. Meningkatkan kepabilitas sistem komputer.

11. Memiliki kemampuan untuk bekerja dengan informasi yang tidak lengkap dan mengandung ketidakpastian.

12. Sebagai media pelengkap dalam penelitian.

13. Meningkatkan kapabilitas dalam penyelesaian masalah.

14. Menghemat waktu dalam pengambilan keputusan.

\section{Kelemahan Sistem Pakar}

Disamping memiliki beberapa keuntungan, sistem pakar juga memiliki beberapa kelemahan, antara lain :

1. Biaya yang diperlukan untuk membuat dan memeliharanya sangat mahal.

2. Sulit dikembangkan. Hal ini tentu saja erat kaitannya dengan ketersediaan pakar dibidangnya.

3. Sistem Pakar tidak 100\% bernilai benar.

\section{Metode Epidemiologi}

Epidemiologi merupakan disiplin ilmu inti dari ilmu kesehatan masyarakat (public health). Profesor Sally Blakley dalam kuliah pengantar epidemiologi pada Tulane School of Public Health and Tropical Medicine, New Orleans, pada 1990 menyebut epidemiologi "the mother science of public health" (Blakley, 1990). Kesehatan masyarakat bertujuan melindungi, memeli-hara, memulihkan, dan meningkatkan kesehatan populasi. Sedang epidemiologi memberikan kontribusinya dengan mendeskripsikan distribusi penyakit pada populasi, meneliti paparan faktor-faktor yang mempengaruhi atau menyebabkan terjadinya perbedaan distribusi penyakit tersebut. Pengetahuan tentang penyebab perbedaan distribusi penyakit selanjutnya digunakan untuk memilih strategi intervensi yang tepat untuk mencegah dan mengendalikan penyakit pada populasi, dengan cara mengeliminasi, menghindari, atau mengubah faktor penyebab tersebut.

\section{Skrining (Penapisan)}

Skrining/penapisan merupakan proses pendeteksian kasus/kondisi kesehatan pada populasi sehat pada kelompok tertentu sesuai dengan jenis penyakit yang akan dideteksi dini dengan upaya meningkatkan kesadaran pencegahan dan diagnosis dini bagi kelompok yang termasuk resiko tinggi. Pada negara maju, umumnya proses skrining/penapisan dilakukan pada penyakit tidak menular, misalnya kanker payudara yang dilakukan pada kelompok beresiko seperti wanita terlahir kembar, ada genetik keluarga, wanita yang tidak menikah, wanita yang tidak menyusui (red ngASI) anaknya dan pola diet dan gaya hidup yang tidak sehat, wanita pengguna $\mathrm{KB}$ hormonal, wanita yang menstruasi pertama dibawah 12 tahun dan menopause diatas 55 tahun. Berikut dijelaskan definisi skrining/penapisan menurut beberapa ahli Epidemiologi. Menurut

Webb (2005), skrining/penapisan merupakan metode test sederhana yang digunakan secara luas pada populasi sehat atau populasi yang tanpa gejala penyakit (asimptomatik). Skrining/penapisan tidak dilakukan untuk mendiagnosa kehadiran suatu penyakit, tetapi untuk memisahkan populasi subjek skrining/penapisan menjadi dua kelompok yaitu orang-orang yang lebih 
beresiko menderita penyakit tersebut dan orang-orang yang cenderung kurang beresiko terhadap penyakit tertentu. Mereka yang mungkin memiliki penyakit (yaitu, mereka yang hasilnya positif) dapat menjalani pemeriksaan diagnostik lebih lanjut dan melakukan pengobatan jika diperlukan.

Menurut Komisi Penyakit Kronis AS (1951) dalam kamus Epidemiologi (A Dictionary of Epidemiology), skrining/penapisan didefinisikan sebagai "identifikasi dugaan penyakit atau kecacatan yang belum dikenali dengan menerapkan pengujian, pemeriksaan atau prosedur lain yang dapat diterapkan dengan cepat. Tes skrining/penapisan memilah/memisahkan orang-orang yang terlihat sehat untuk dikelompokkan menjadi kelompok orang yang mungkin memiliki penyakit dan kelompok orang yang mungkin sehat. Sebuah tes skrining/penapisan ini tidak dimaksudkan untuk menjadi upaya diagnosa. Orang dengan temuan positif menurut hasil skrining/penapisan atau suspek suatu kasus harus dirujuk ke dokter untuk diagnosis dan menjalani pengobatan yang diperlukan.

\section{Prinsip Dalam Skrining (Penapisan)}

Untuk menghasilkan program skrining/penapisan yang bermanfaat bagi masyarakat luas, harus ada kriteria tertentu dalam memilih penyakit apa yang akan diskrining/penapisan. Berikut beberapa katrakteristik penyakit yang harus dipertimbangkan dalam memutuskan kebijkan skrining/penapisan.

1. Jenis penyakit harus termasuk jenis penyakit yang parah, yang relatif umum dan dianggap sebagai masalah kesehatan masyarakat oleh masyarakat.

2. Skrining/penapisan harus aman dan dapat diterima oleh masyarakat luas. Dalam proses skrining/penapisan membutuhkan partisipasi dari masyarakat yang dinilai cocok untuk menjalani pemeriksaan. Oleh karena itu skrining/penapisan harus aman dan tidak mempengaruhi kesehatannya.

3. Skrining/penapisan harus akurat dan reliable. Tingkat akurasi menggambarkan sejauh mana hasil tes sesuai dengan keadaan yang sebenarnya dari kondisi kesehatan/penyakit yang diukur. Sedangkan reliabilitas biasanya berhubungan salah satu dengan standardisasi atau kalibrasi peralatan pengujian atau keterampilan dan keahlian dari orang-orang menginterpretasikan hasil tes.

4. Harus mengerti riwayat alamiah penyakit dengan baik dan percaya bahwa dengan melakukan skrining/penapisan maka akan menghasilkan kondisi kesehatan yang jauh lebih baik.

5. Skrining/penapisan akan sangat bermanfaat jika dilakukan pada saat yang tepat.

6. Kebijakan, prosedur dan tingkatan uji harus ditentukan untuk menentukan siapa yang harus dirujuk untuk pemeriksaan, diagnosis dan tindakan lebih lanjut.

\section{Metode Pengumpulan Data}

Untuk memperoleh data yang diperlukan dalam penyusunan penelitian ini dengan menggunakan metode pengumpulan data sebagai berikut:

1. Wawancara atau interview

Melakukan tanya jawab langsung kepada beberapa Dokter umum atau perawat dan juga pendidik kesehatan masyarakat guna analisis tentang metode epdemiologi skrining tes kesehatan, serta mewawancarai pihak PSDM CV. Annisa untuk konsultasi prosedure yang sudah ada guna analisis untuk membangun sistem aplikasi pada penelitian ini.

2. Pengamatan Langsung atau Observasi. Mengamati langsung proses skrining yang telah dilakukan oleh pihak kesehatan pada umumnya, yang mana dengan metode epidemiologi dilakaukannya skrining tes kesehatan dengan melakukan sejumlah pertanyaan yang sudah ada pada umumnya.

3. Studi Pustaka

Pengumpulan data dengan menggunakan buku-buku dan pencarian di internet sebagai bahan referensi dalam penulisan laporan dan pembuatan sistem.

\section{Tahap-Tahap Pembuatan Sistem}

Dalam pengembangan sistem ini, ada beberapa tahapan yang harus dilakukan. Adapun tahapan tersebut adalah sebagai berikut: 
1. Analisis Sistem yang berjalan

a) Pengukuran waktu tes kesehatan di Puskesmas atau Dokter memerlukan waktu kurang lebih sekitar $60-120$ menit

b) Hasil keterangan tes kesehatan dibuat dengan tulis tangan yang memerlukan waktu $10-20$ menit

\section{Analisis Kebutuhan Sistem}

a) Penggunaan aplikasi skrining tes kesehatan dalam menjawab pertanyaan memerlukan waktu $10-30$ menit

b) Sistem dapat menghitung langsung secara otomatis perhitungan hasil berat badan ideal dan indeks masa tubuh

c) Sistem dapat menampilkan pertanyaan skrining tes kesehatan dan mengakumulasi hasil jawaban secara otomatis

d) Hasil tes skrining menggunakan aplikasi bisa langsung terlihat setelah melaksanakan tes

\section{Perancangan Sistem}

Proses perancangan yang baik diperlukan untuk pembuatan program tak terkecuali dalam pembuatan aplikasi yang baik. Perancangan sistem secara terperinci, dilakukan dengan cara:

\section{Flowchart Sistem Aplikasi}

Skema alur urutan proses sistem secara logika, dari awal memulai aplikasi skrining hingga selesai hasil skrining.

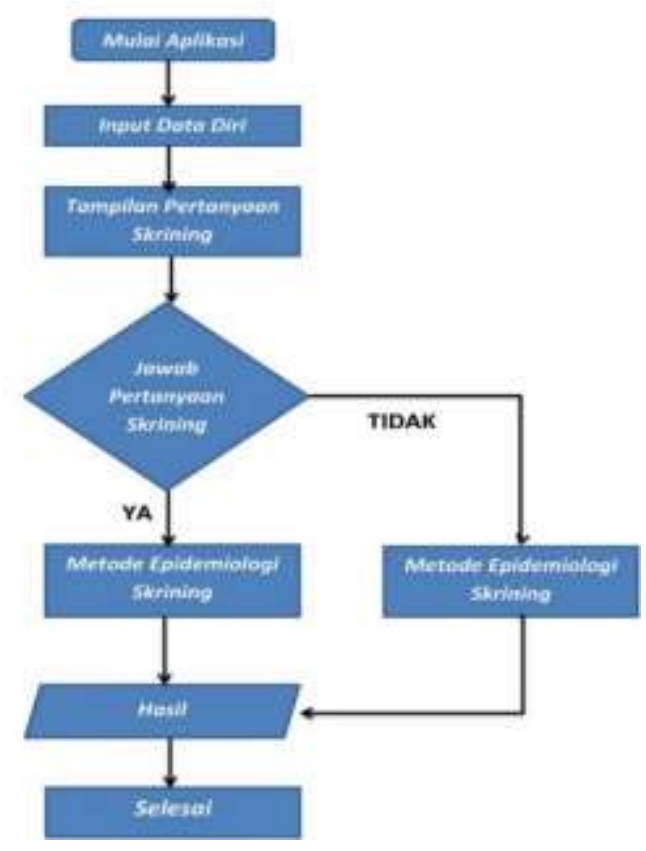

Gambar 1. Flowchart Aplikasi Skrining

\section{HASIL DAN PEMBAHASAN}

\section{Implementasi}

Tahap implementasi sistem dilakukan penerjemahan kebutuhan pembangunan aplikasi kesehatan menggunakan metode epidemiologi skrining tes untuk karyawan CV. Annisa kedalam representasi perangkat lunak sesuai dengan hasil analisis yang telah dilakukan. Setelah implementasi maka dilakukan pengujian sistem yang baru dimana akan dilihat kekurangan - kekurangan pada aplikasi yang baru untuk selanjutnya diadakan pengembangan sistem.

\section{Spesifikasi Sistem Aplikasi}

Pada spesifikasi sistem aplikasi kesehatan menggunakan metode epidemiologi skrining tes untuk karyawan CV. Annisa menggunakan spesifikasi perangkat keras dan perangkat lunak sebagai berikut ;

1. Perangkat keras pendukung

- Processor Amd Dual-Core

- RAM 2 GB DDR3

- LCD 14 Inch

- Hardisk 320 GB 
2. Perangkat lunak pendukung

- Sistem Operasi Windows 7

- Pemprograman Delphi 7

- Data Base Xamp My SQL

\section{Tampilan Antar Muka Aplikasi}

\section{Halaman Login Aplikasi}

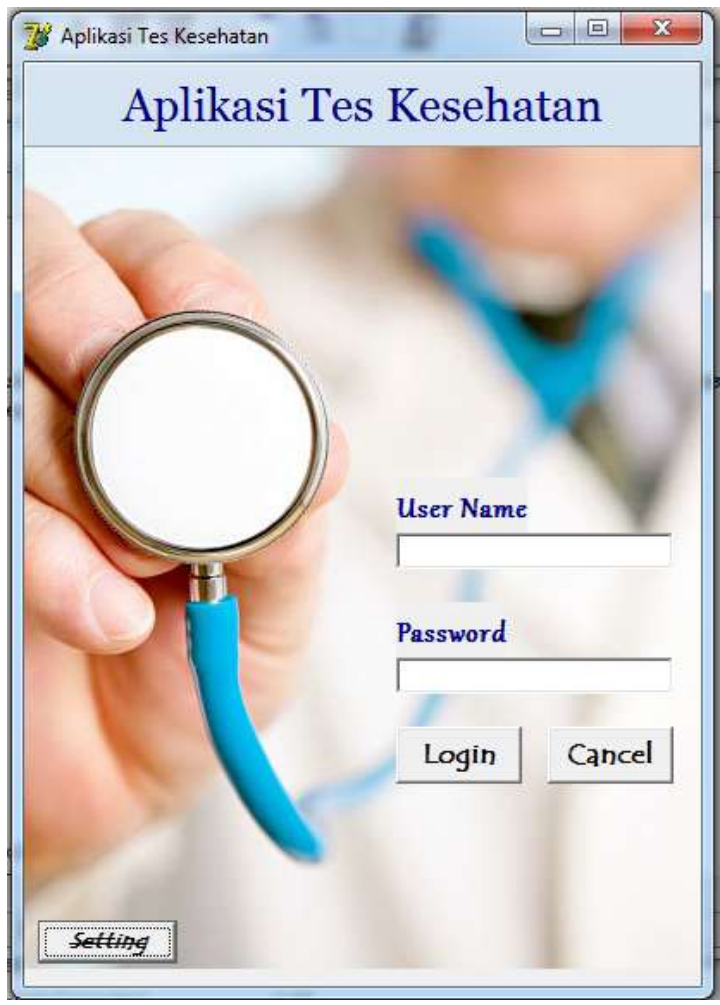

Gambar 2. Halaman Login Aplikasi

Pada halaman login aplikasi terdapat tombol setting digunakan untuk setting administrator dan tombol login sebagai awal masuknya peserta untuk tes kesehatan.

\section{Tampilan Input Data Diri}

Pada form pengisian data diri, peserta melengkapi data diri untuk kelengkapan data.

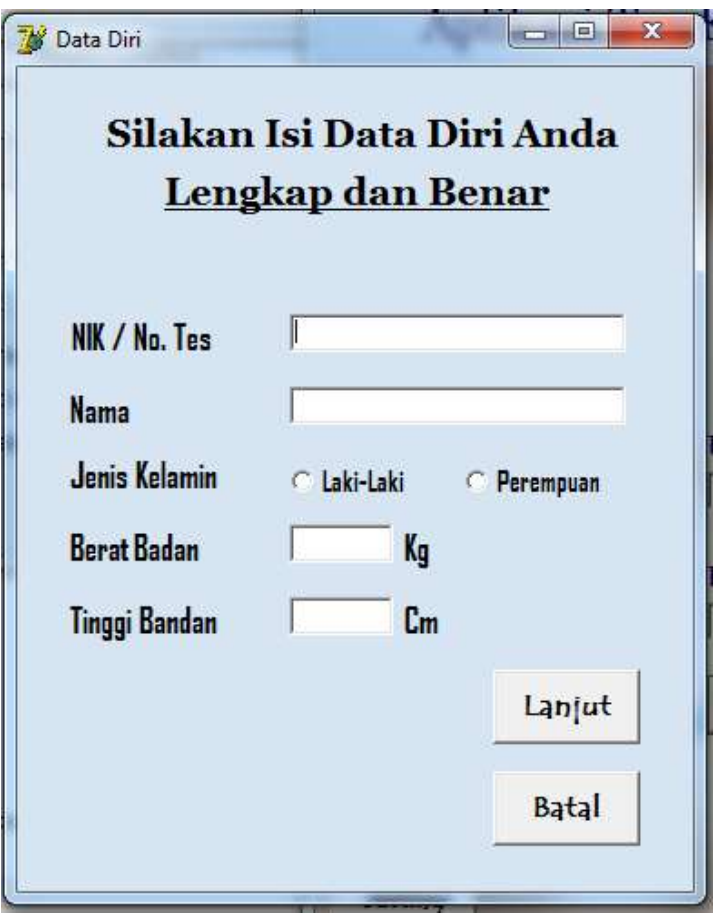

Gambar 3. Input Data Diri

\section{Tampilan Proses Tes Kesehatan}

Pada proses tes kesehatan form ini peserta mengisi jawaban dari beberapa pertanyaan seputar tentang riwayat kesehatan, pola makanan, riwayat penyakit keluarga, dan riwayat penyakit pribadi.

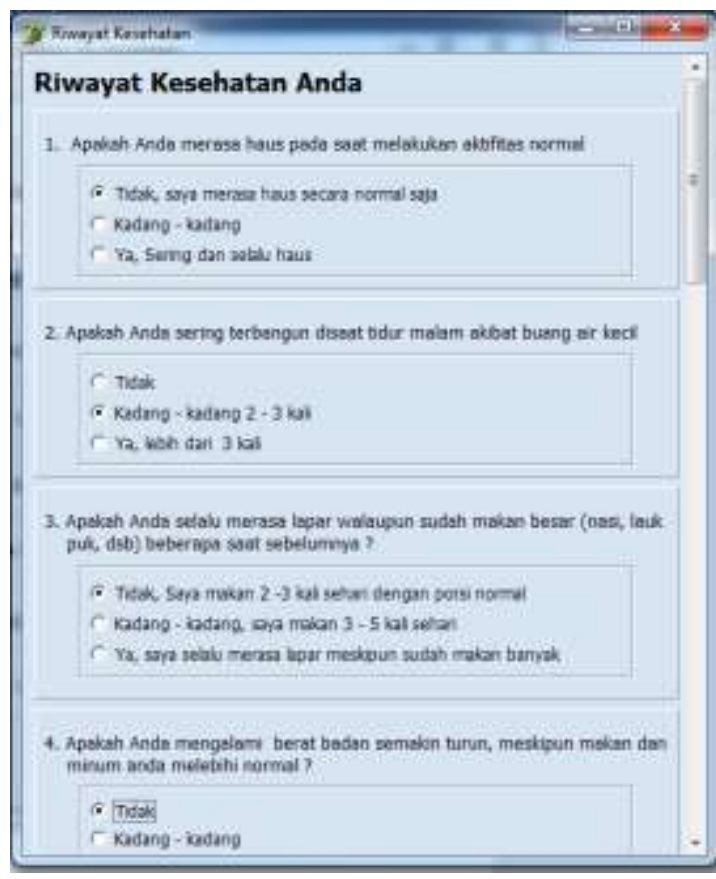

Gambar 4. Tampilan Proses Tes Kesehatan 


\section{Tampilan Hasil Tes Kesehatan}

Pada hasil tes kesehatan form ini peserta tes mengetahui hasil skrining tes kesehatan yang mana terlihat hasil berat badan ideal untuk peserta tes, hasil indeks masa tubuh yang diketahui angka dan keteangannya, serta perhitungan hasil dari 4 penyakit Diabetesmiletus, Hipertensi, Jantung koroner, Ginjal Kronik dengan keterangan Rendah, Sedang dan Tinggi.

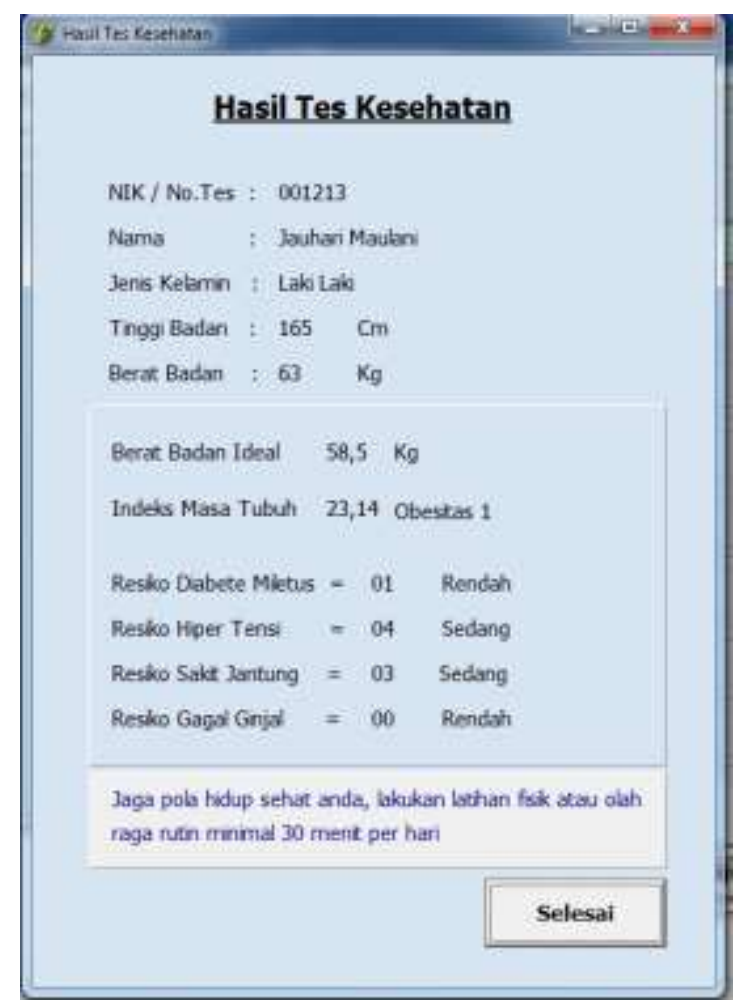

Gambar 5. Tampilan Hasil Tes Kesehatan

\section{KESIMPULAN}

Berdasarkan hasil dari penelitian dan pembahasan yang telah dikemukakan, dapat ditarik kesimpulan, kesimpulan tersebut yaitu :

1. Pembangunan aplikasi kesehatan menggunakan metode epidemiologi skrining tes untuk karyawan CV. Annisa yang diusulkan dapat membuat pengetesan kesehatan secara cepat dan efisien sesuai dengan data yang ada.

2. Pengolahan data yang berubah dari sistem manual ke sistem berbasis komputer lebih efisien dan efektif dalam hal melakukan pekerjaan yang ada pada perusahaan.

\section{DAFTAR PUSTAKA}

[1] A.S, Rosa. M. Shalahudin. (2015, September). Rekayasa Perangkat Lunak

[2] Terstruktur dan Berorientasi Objek. Bandung. Informatika

[3] Doenges, Marilynn E. DKK. 2014. Manual Diagnosis Keperawatan. Jakarta.EGC

[4] Fadli, Ari. 2003 - 2010. Sistem Pakar Dasar. Retrieved juli 14, 2017, from https : IlmuKomputer.com

[5] Ferdinand, M. (2015, April 18). Sistem Informasi. Retrieved Juli 12, 2017, from http://apr11-si.comuf.com/SI.pdf

[6] Kadir, Abdul. 2008. Mudah Menjadi Programmer Delphi. Yogyakarta. Andi

[7] Murti Bhisma, 2012. Pengantar Epidemiologi. Retrieved juli 18, 2017 , from https://id.scribd.com/mobile/doc

[8] Pranata, Antony. 2005. Algoritma dan Pemrograman. Yogyakarta. J \& J Learning

[9] Queen, Najmah. 2014. Definisi Dan Prinsip Pelaksanaan Skrining (Penapisan). Retrieved juli 15, 2017. http :// http://metopidfkmunsri.blogspot.co.id

[10] Subekti, M. (1997). Sistem manajemen Basis Data. Jakarta: Universitas Bina Nusantara. 